\title{
Synaptic Vesicle Pools and Dynamics
}

\author{
AbdulRasheed A. Alabi ${ }^{1}$ and Richard W. Tsien ${ }^{1,2}$ \\ ${ }^{1}$ Department of Molecular and Cellular Physiology, Stanford Institute for Neuro-Innovation \\ and Translational Neurosciences, Stanford Medical School, Stanford, California \\ 94305 \\ ${ }^{2}$ NYU Neuroscience Institute and Department of Physiology and Neuroscience, \\ New York University, New York, New York 10016 \\ Correspondence: Richard.tsien@nyumc.org
}

Synaptic vesicles release neurotransmitter at chemical synapses, thus initiating the flow of information in neural networks. To achieve this, vesicles undergo a dynamic cycle of fusion and retrieval to maintain the structural and functional integrity of the presynaptic terminals in which they reside. Moreover, compelling evidence indicates these vesicles differ in their availability for release and mobilization in response to stimuli, prompting classification into at least three different functional pools. Ongoing studies of the molecular and cellular bases for this heterogeneity attempt to link structure to physiology and clarify how regulation of vesicle pools influences synaptic strength and presynaptic plasticity. We discuss prevailing perspectives on vesicle pools, the role they play in shaping synaptic transmission, and the open questions that challenge current understanding.

$\mathrm{N}^{\mathrm{e}}$ urons are uniquely polarized cells for receiving and transmitting information. Neurotransmission, a form of chemical communication between neurons, occurs at anatomically specialized sites termed synapses. An action potential (AP) propagates along a neuron's transmitting axon and depolarizes "buttonlike" axonal swellings known as synaptic boutons. Within these presynaptic structures, AP-driven elevations in intracellular calcium $\left(\mathrm{Ca}^{2+}\right)$ trigger neurotransmitter release onto a postsynaptic target, typically another neuron. This signal transfer underlies the function of neural networks critically important for human behaviors ranging from coordination of move- ment to cognitive functions such as perception, thought, learning, and memory.

The mid-20th century ushered in revolutionary understanding of the components of neurotransmission, both electrical (Hodgkin and Huxley 1952) and chemical (Fatt and Katz 1952; Del Castillo and Katz 1954). In particular, Bernard Katz developed the quantal theory of transmitter release-that neurotransmitter molecules were released in discrete packetsin elegant studies with José del Castillo and Paul Fatt. This work, alongside the first electron microscope (EM) images of the synapse (Sjostrand 1953; Palade 1954; Palay 1954; De Robertis and Bennett 1955), led to the vesicular

Editors: Morgan Sheng, Bernardo Sabatini, and Thomas C. Südhof

Additional Perspectives on The Synapse available at www.cshperspectives.org

Copyright (C) 2012 Cold Spring Harbor Laboratory Press; all rights reserved; doi: 10.1101/cshperspect.a013680

Cite this article as Cold Spring Harb Perspect Biol 2012;4:a013680 
hypothesis of neurotransmission, which posited that transmitter is stored in synaptic vesicles and that release from the vesicle interior forms the structural basis for quantal neurotransmission (Del Castillo and Katz 1956; Palay 1956).

Recent ultrastructural images of mammalian central synapses typify presynaptic architecture, featuring synaptic vesicles (SV) numbering between several dozen and a thousand. Some vesicles localize adjacent to a proteinrich, electron-dense active zone (AZ) where fusion is thought to occur, whereas others are scattered within the greater bouton area (Schikorski and Stevens 1997) as illustrated in Figure 1A. Studies of vesicle-mediated neurotransmission have provided fundamental insights into the mechanisms that mediate transmitter uptake into vesicles (Blakely and Edwards 2012), calcium-dependent fusion of vesicles with the plasma membrane (Südhof and Rizo 2011; Südhof 2012), and critical modes of vesicle retrieval (Harata et al. 2006), without which the nerve terminal area would expand enormously (Bittner and Kennedy 1970). Four decades of such work has generated abundant information about the synaptic vesicle cycle, which chronicles the states occupied by a vesicle before and after fusion (Heuser and Reese 1981; Murthy and De Camilli 2003; Südhof 2004).

SVs are therefore vital structural components to the function of presynaptic terminals. Disruptions in vesicle function create deficits in neurotransmission that underlie various forms of neurological or psychiatric disorders (Waites and Garner 2011). Consequently, dissecting the physiological properties of SVs is important for understanding the workings of transmitter release in both health and disease.

\section{VESICLE HETEROGENEITY SHAPES SYNAPTIC TRANSMISSION: A PRIMER FOR POOLS}

Aside from obvious differences in spatial location, no other morphological features clearly distinguish vesicles within a bouton. Why then must vesicles be grouped into distinct pools? An important step in understanding vesicle pools is to frame their relevance to fundamental aspects of neurotransmitter release.

Early experiments at the neuromuscular junction (NMJ) detected a phenomenon of synaptic depression (Fig. 1B) wherein the postsynaptic response to repetitive presynaptic APs declined reproducibly over time (Liley and North 1953; Lundberg and Quilisch 1953). Quantal analysis suggested the depression occurred presynaptically, indicated by little or no change in the unitary postsynaptic response, but a progressive reduction in the number of transmitter-laden packets released by each AP. Two pioneering studies hypothesized that during the development of depression from frequent stimulation, quanta are released from a limited pool of "release-ready" vesicles (emptying the pool) at a rate faster than fresh transmitter-filled vesicles could replenish those expended (refilling the pool) (Birks and Macintosh 1961; Elmqvist and Quastel 1965). Assuming that each AP discharges a similar fraction of available vesicles, a decrease in release is expected to follow the depletion of this limited pool. Transmission strength eventually reaches a lower steady level, in which release is perfectly balanced by the slow refilling. Frequency-dependent increases in the kinetics and magnitude of synaptic depression conformed to this hypothesis. Importantly, the maximal size of this pool, expressed in functionally determined quantal units, was far below the number of vesicles estimated from morphology. This implied the existence of some nonuniformity in the availability of vesicles for release: Only a fraction of the total ensemble is "release-ready" and additional vesicles are recruited to replenish this limited pool (Fig. 1B). Notably, the "release-ready" pool and its replenishment or refilling were functionally defined without specification of cell biological mechanism, an ambiguity that still persists.

Synaptic Depression Links Vesicle Dynamics to Network Performance

Synaptic depression is one of a wide variety of reversible changes in synaptic strength collectively termed short-term plasticity (STP). These operate on relatively rapid timescales (milliseconds 
A

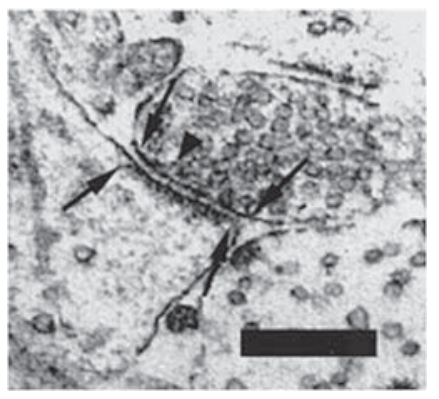

B

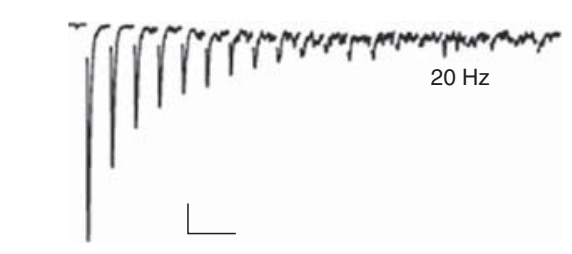

\section{C}

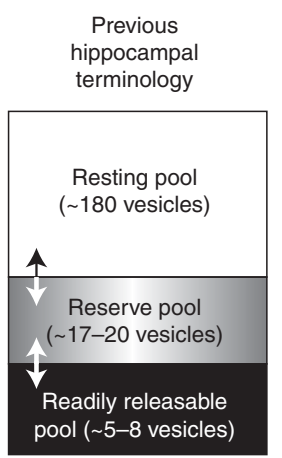

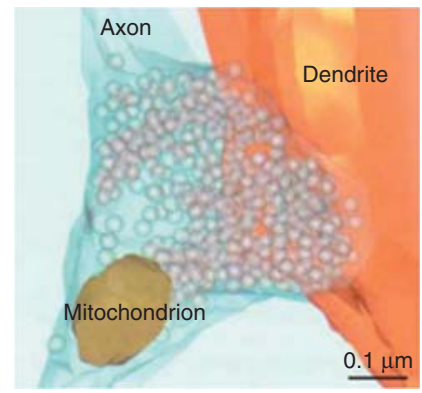
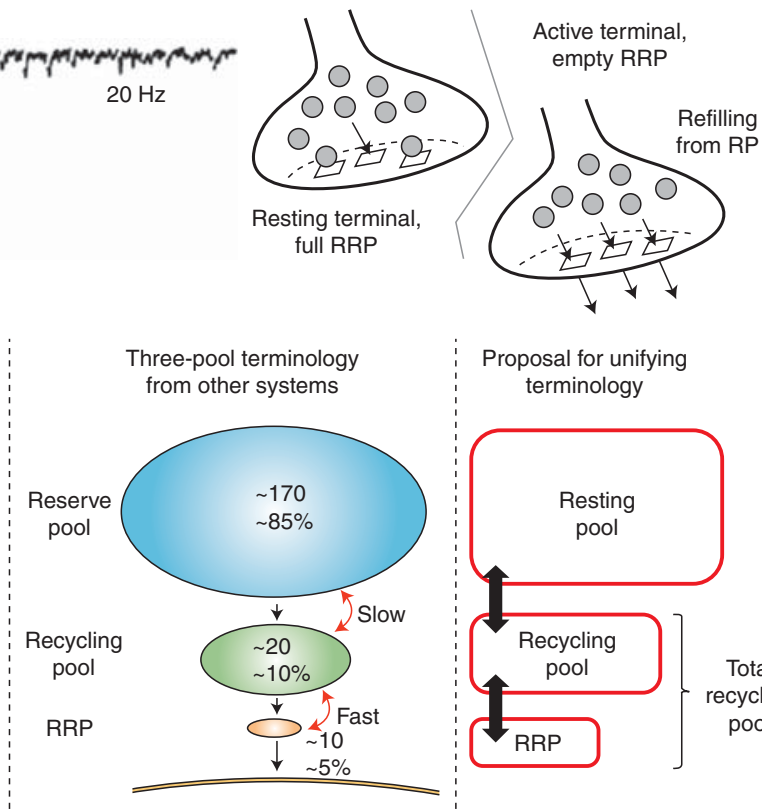

Figure 1. Release dynamics and vesicle pool terminology. (A) Left panel: Ultrastructural image from mouse hippocampal neurons in culture. Boundaries of the presynaptic active zone and postsynaptic density (arrows) anatomically define a synaptic contact. Few vesicles appear docked to the active zone (example arrowhead), whereas the vast majority are distributed within the greater bouton volume. Scale bar, $0.25 \mu \mathrm{m}$ (Schikorski and Stevens 1997). Right panel:3D reconstruction of serial sections like those in $(A)$ displays overall architecture of synapse and vesicles, devoid of any distinguishing morphological features. (B) Left panel: Synaptic depression recorded from postsynaptic responses in hippocampal synapses during $20 \mathrm{~Hz}$ stimulation. Note the increase in asynchronous release, occurring between the large-amplitude synchronous peaks, during the stimulus train. Scale bars, $500 \mathrm{~ms}$ and 100 pA (Stevens and Williams 2007). Right panel: Simple model suggesting depression results from sequential recruitment of functionally heterogeneous vesicle pools. Depletion of a readily releasable pool (RRP) of vesicles gives way to a rate-limiting refilling process from a general recycling pool (RP). (C) Vesicle pool terminology from hippocampal terminals (left panel) (Südhof 2000) and an alternative three-pool model (middle panel) (Rizzoli and Betz 2005). A proposed unifying scheme (right panel) avoids the conflicting term "reserve pool"and merges the remaining terminology for the final lexicon used in this review. Arrows denote interconversion of vesicles between pools and numerical values represent absolute number or relative percentage of vesicles within each pool (see text for more details). (Left side of Panel $A$ is from Schikorski and Stevens 1997; reprinted, with permission, from J Soc Neurosci (C) 1997; right side of Panel A is from Rizzoli and Betz 2005; reprinted, with permission, from Macmillan Publishers Ltd., Nat Rev Neurosci (C) 2005 (originally sourced from Schikorski and Stevens 2001, Nat Neurosci (C) 2001; left side of Panel B is from Stevens and Williams 2007; reprinted, with permission, from the American Physiological Society (C) 2007; right side of panel B is from Wesseling and Lo 2002; reprinted, with permission, from J Soc Neurosci (C) 2002; left side of Panel C is from Südhoff 2000; reprinted, with permission, from Elsevier (C) 2000; middle of Panel C is from Rizzoli and Betz 2005; reprinted, with permission, from Nature Rev Neurosci (C) 2005.) 
to minutes) and shape information processing at synapses (Abbott and Regehr 2004). If the onset of depression is relatively slow, the postsynaptic response follows the frequency of presynaptic inputs and is able to encode such information. Conversely, if depression develops rapidly, the postsynaptic cell preferentially encodes the temporal onset of presynaptic activity, losing significant broadband information, particularly at higher AP frequencies (Tsodyks and Markram 1997). In cortical synapses, depression performs a dynamic "gain control" function that contributes to regulation of neuronal sensitivity during rapid changes in sensory input (Abbott et al. 1997). Furthermore, during pathological episodes of neuronal hyperactivity, depression provides negative feedback that can help set limits on runaway network activity. The link, therefore, between synaptic depression and the depletion of SVs with heterogeneous release properties exemplifies the impact of vesicle dynamics on neural circuit performance.

\section{A Caveat about Mechanisms for Depression Other than Vesicle Depletion}

Synaptic depression likely includes a diversity of other determinants in various neuronal preparations (Zucker and Regehr 2002). For example, at the calyx of Held, synaptic depression is accompanied by use-dependent decreases in presynaptic $\mathrm{Ca}^{2+}$ current (Xu and $\mathrm{Wu} 2005$ ), possibly resulting from $\mathrm{Ca}^{2+}$ accumulation and $\mathrm{Ca}^{2+}$ channel inactivation (Mochida et al. 2008). In addition, AP failures (Bielefeldt and Jackson 1993), activation of presynaptic inhibitory autoreceptors (Wu and Saggau 1997), release site inactivation (Armitage and Siegelbaum 1998), and postsynaptic receptor desensitization (Otis et al. 1996) or saturation (Neher and Sakaba 2001) have also been found to contribute to depression in diverse systems. Attempts at assignment of mechanism have only been performed in a limited number of model synapses (Kraushaar and Jonas 2000; Schneggenburger et al. 2002; Mochida et al. 2008). However, vesicle depletion remains a widely accepted contributor to depression in most, if not all, neuronal preparations (Zucker and Regehr 2002).
General Relevance of Pools to Presynaptic Release

Vesicle pools are relevant to presynaptic physiology in other ways, particularly with regard to synaptic release probability $\left(\mathrm{P}_{\mathrm{r}}\right)$ and presynaptic determinants of synaptic strength.

$\mathrm{P}_{\mathrm{r}}$ is a measure of synaptic reliability, which quantifies the likelihood that an AP triggers the release of at least one vesicle from a bouton. Unlike the NMJ, most central synapses are relatively unreliable $\left(\mathrm{P}_{\mathrm{r}}<0.3\right.$ on average in hippocampal terminals [Murthy et al. 1997]) with $\mathrm{P}_{\mathrm{r}}$ varying widely between boutons in a manner that correlates with the number of "releaseready" vesicles $(N)$ (Dobrunz and Stevens 1997; Murthy et al. 2001; but see Hanse and Gustafsson 2001b). Moreover, the " $N$ " release-ready vesicles and their average fusion probability $\left(P_{\text {ves }}\right)$ establish the quantal content of an AP response and together reflect presynaptic contributions that set synaptic strength (Allen and Stevens 1994; Stevens and Wang 1994).

In the setting of activity-dependent changes in $\mathrm{P}_{\mathrm{r}}$ (Hessler et al. 1993; Rosenmund et al. 1993), synaptic strength can be significantly altered (Stevens and Wesseling 1999a,b; Schneggenburger et al. 2002), quite notably during periods of synaptic plasticity (Stevens and Wang 1994, 1995; Goda and Stevens 1998) and homeostasis (Murthy et al. 2001). Conceivably, some of these changes may have mechanistic origins in alterations to all vesicle pools (Murthy et al. 2001), selective modulation of the "releaseready" pool (Goda and Stevens 1998), or reallocation of existing vesicles between functional pools (Waters and Smith 2002; Ratnayaka et al. 2012). Thus, beyond synaptic depression by vesicle depletion, vesicle pools account for a variety of presynaptic mechanisms that support the regulation of synaptic strength, plasticity, and by extension, learning, memory, and behavior.

\section{A WORKING DEFINITION OF VESICLE POOLS}

There are multiple ways of "pooling" vesicles that are complementary but have yet to coalesce. Morphology tends to focus on the spatial 
localization of vesicles relative to the AZ. Electrophysiological recordings apply compartmental analysis and laws of mass action to define a pool as a functional group. Biochemical studies can aspire to define distinct groups of vesicles by a specific molecular label. Location, functionality, and molecular features must all matter in the end, but currently there is incomplete consensus about the experimental approach to be used to define pools in a quantitative way, and the very terminology used to frame the research questions is itself a matter of debate.

\section{Common Features of Vesicle Pool Organization among Diverse Synapses}

In a thoughtful and elegant review, Rizzoli and Betz (2005) considered different preparations that have been used to study vesicle pools: the motor nerve terminals of frog and fly; the calyx of Held of the auditory brain stem and hippocampal nerve terminal, both from rodents; and the ribbon synapse of the goldfish. These five systems, and another famous invertebrate preparation, the squid giant synapse, encompass an enormous range of presynaptic structures, varying in function, size, and organization, and excelling in particular ways. The frog neuromuscular synapse is the most classical system; that of the fly is the most amenable to genetic manipulation; the large calyx of Held synapses are the most accessible to powerful experimental approaches, including measurements of presynaptic capacitance; and the ribbon synapse is arguably most highly evolved in doing its job successfully.

Although the large synapses offer important kinds of experimental accessibility, we have chosen to center this review on the tiniest synaptic terminals, exemplified by hippocampal or neocortical synapses studied in brain slices and dissociated cultures. Although studies of these synapses face technical challenges because of their size and relative inaccessibility, there are countervailing considerations. Small nerve terminals constitute the vast majority of central nervous system (CNS) synapses, reflecting a miniaturization of brain components critical for massive parallel processing in an anatomical structure of limited size. Disorders in the functioning of such synapses are of relevance to human diseases ranging from autism to Alzheimer's disease, or from ataxia to epilepsy. Generally they comprise only a single AZ, which is advantageous if one accepts that synapses of various sizes use a modular architecture built around a fundamental unit: the single AZ plus its attendant vesicles. In support of this view, the calyx of Held can be thought of as 600 of such units, operating in parallel. In this respect, the small CNS synapse could be regarded as an excellent model for the famous Calyx! Small CNS synapses stand out because their vesicle pools are easily depleted, and thus provide a foil for other kinds of central synapses with large pools of vesicles that are replenished quickly enough to sustain high bandwidth transmission (Hallermann et al. 2003, 2010; Saviane and Silver 2006). The goal therefore is to start with this one experimental system, but to define principles for naming, defining, and manipulating vesicle pools that could be applicable to other systems as well.

\section{Basic Features of Vesicle Pools in CNS Terminals and Proposal for a Unifying Nomenclature}

In virtually every mature neuronal preparation, a class of "release-ready" vesicles has been defined and named the readily releasable pool (RRP). In hippocampal terminals, only a few vesicles are endowed with RRP status and these are readily discharged after only a couple of seconds at $10-40 \mathrm{~Hz}$ stimulation (Stevens and Williams 2007). After the RRP has been depleted, continued release occurs from a secondary releasable pool we choose to call the recycling pool (RP). Together all vesicles capable of undergoing release, RRP and RP, are grouped into a total recycling pool (TRP).

Paradoxically, however, this TRP still represents only a fraction of the $\sim 100-200$ (Schikorski and Stevens 1997) or up to $\sim 500$ (Harris and Sultan 1995) morphologically identified vesicles in hippocampal terminals, prompting the designation of yet another pool of vesicles, 
the resting pool $\left(\mathrm{R}_{t} \mathrm{P}\right)$. In a series of recent studies expanded upon in a later section, several potential roles for the $\mathrm{R}_{\mathrm{t}} \mathrm{P}$ are highlighted.

Rizzoli and Betz previously proposed a unifying three-pool model that comprised an RRP, RP, and "reserve pool," which are accessed for release in sequential order. In this scheme, the RRP is immediately available for release, the RP replenishes the RRP during "physiological" patterns of stimulation, and the "reserve pool" is only released during bouts of intense, often "unphysiological" stimulus patterns (Rizzoli and Betz 2005). In aligning with this nomenclature, we preserve the RRP-to-RP sequence but note that the "reserve pool" definition contradicts a prior designation of the same term in central synapses. For clarity, we choose to create an equivalent three-pool model by replacing "reserve pool" with the previously defined resting pool, $\mathrm{R}_{\mathrm{t}} \mathrm{P}$ (Fig. 1C). This distinction is subtle but important given some unique differences between the hippocampal $\mathrm{R}_{\mathrm{t}} \mathrm{P}$ and the "reserve pool" described, for instance, at the frog NMJ (Harata et al. 2001b; Richards et al. 2003).

\section{EXPERIMENTAL CHARACTERIZATION OF CANONICAL VESICLE POOLS}

Several robust strategies have been applied to the characterization of SV pools and dynamics. In addition to vesicle fusion and retrieval at the plasma membrane, studies have greatly expanded to explore vesicle dynamics within the interior of the bouton. Using different optical tools, vesicles can be tracked with novel, dynamic imaging techniques in live neurons (Shtrahman et al. 2005), with superior spatiotemporal resolution (Willig et al. 2006) and signal to noise (Park et al. 2012). A summary of these methods is provided in Box 1 . The remarkable diversity of this toolbox has allowed probing of SVs throughout the vesicle cycle and led to new insights into their dynamics.

\section{Total Recycling Pool (TRP)}

Sizing up the number of vesicles in the TRP $\left(N_{\text {TRP }}\right)$ has largely relied on optical probes of vesicle fusion (Box 1). In hippocampal syn- apses, for example, strong stimulation in the continued presence of extracellular FM dye results in a saturating degree of dye loading within boutons (Ryan et al. 1996; Harata et al. 2001b), as every releasable vesicle eventually fuses and entraps dye on subsequent endocytosis. The peak FM signal can be normalized to that of a single vesicle (Murthy et al. 1997; Harata et al. 2001a) to obtain TRP estimates of $\sim 30$ vesicles, similar to those made with uptake of single quantum dots (QDs) (Zhang et al. 2007). There is general agreement that the TRP is only a fraction of the morphological vesicle pool, but the exact fraction differs according to experimental strategy (Harata et al. 2001b; Fernandez-Alfonso and Ryan 2008; Ikeda and Bekkers 2009). Using strong stimulation and the most direct method, ultrastructural identification of FMcontaining vesicles after photoconversion, the TRP averaged $\sim 15 \%$ of vesicles (Harata et al. 2001a). Interestingly, the largest estimate, using electrophysiological readouts, suggests that up to $\sim 80-130$ vesicles ( $\sim 70 \%$ of all vesicles) can be released during mild stimulation over a long period (Ikeda and Bekkers 2009), although correlative morphology is needed for a more direct confirmation.

\section{Readily Releasable Pool (RRP)}

RRP vesicles have the highest fusion probability at the bouton, and this accounts for their particularly weighty contribution to synaptic strength (Dobrunz and Stevens 1997; Waters and Smith 2002). By definition, they are the first to be released and thus depleted during a bout of activity (Rosenmund and Stevens 1996; von Gersdorff et al. 1996; Schneggenburger et al. 2002; Richards et al. 2003). For burst-pattern firing, typical of the hippocampus in vivo (Fenton and Muller 1998), synapses respond robustly at first but then progressively weaken as depletion of RRP vesicles and synaptic depression ensue (Dobrunz and Stevens 1999; Dekay et al. 2006).

The number of RRP vesicles $\left(N_{\mathrm{RRP}}\right)$, on average $\sim 5-9$ vesicles at individual hippocampal boutons (Dobrunz and Stevens 1997; Murthy and Stevens 1999), has often occupied center stage in pool studies because of its impact on 


\section{BOX 1. TOOLS AND METHODS OFTEN USED IN THE STUDY OF VESICLE POOLS AND DYNAMICS}

pHluorin - pHluorin is a green fluorescent protein (GFP) variant that can be genetically encoded onto the lumenal portion of SV proteins. pHluorin fluorescence $\left(\mathrm{pK}_{\mathrm{a}} \sim 7.1\right)$ is quenched at the acidic $\mathrm{pH}$ of the vesicle and fluoresces on fusion and exposure to near-neutral extracellular $\mathrm{pH}$. An acute application of bafilomycin (baf), an inhibitor of the proton pump responsible for acidifying vesicles, allows the pHluorin signal to reflect net exocytosis as vesicles retrieved after fusion fail to reacidify. Ammonium chloride, which neutralizes the interior of acidic organelles, is also useful to unquench recycling and nonrecycling pHluorin-tagged proteins.

FM dyes-Of these small styryl dyes, FM1-43 is most widely used in vesicle studies. It has a significant increase in quantum yield on partitioning into membranes and is trapped within vesicles in a quantized manner after compensatory endocytosis. It remains fluorescent within the inner leaflet of the vesicular membrane until another round of exocytosis, allowing vesicular movement within the bouton to be tracked and providing a signal indicative of fusion pore opening as this causes a loss of dye from the interior of the vesicle.

Quantum dots-QDs are semiconductor-based nanoparticles that have recently been applied to the study of SVs. A major benefit to the QD is the remarkable stability and brightness to its photoluminescence, which allows long-term tracking of QD-labeled structures with substantial signal to noise and little to no photobleaching. The QD size allows uptake into vesicles during endocytosis in a $1: 1$ ratio and is only liberated during release, which involves a full collapse of the QD-loaded vesicle into the plasma membrane.

Photoconversion - In this procedure, FM dye-loaded synapses can be exposed to the chemical $3,3^{\prime}$-diaminobenzidine (DAB) and prolonged photoillumination causes excitation-induced conversion of DAB to an electron-dense product only in dye-containing vesicles. This can be visualized by EM in attempts to provide a morphological correlate to functional observations made using the same dyes.

Stimulating presynaptic release - In addition to high-frequency stimulation (HFS) and hypertonic sucrose, release can be induced by extracellular $\mathrm{K}^{+}$depolarization, brief step depolarizations under voltage-clamp and flash photolysis of caged $\mathrm{Ca}^{2+}$ compounds within the presynaptic bouton. Hypertonic sucrose has been used routinely at the NMJ and central terminals. HFS typically involves eliciting APs in the range of $5-100 \mathrm{~Hz}$ and is often the method of choice in the NMJ but is also used extensively in hippocampal terminals and somewhat in the calyx of Held. Voltage-clamp and $\mathrm{Ca}^{2+}$ uncaging are routinely used in synaptic preparations like the calyx of Held and retinal bipolar neurons that have large terminals accessible to a patch pipette.

Measuring presynaptic output-Optical probes such as FM dyes, pHluorin, and QD nanoparticles have all been applied to the detection of vesicle fusion. In addition, electrophysiological recordings in the postsynaptic cell measure changes in membrane potential or current owing to the release of neurotransmitter and patch clamp measurements in the presynapse of large terminals like the calyx allow the detection of capacitance changes that occur on vesicle membrane fusion with the plasma membrane surface area. For oxidizable transmitters, like dopamine, amperometry allows the specific detection of transmitter presence in the synaptic cleft.

Intrabouton vesicles tracking - This requires good signal-to-noise ratio and the application of superlocalization, subdiffraction resolution or statistical methods because of the relatively small size of synaptic vesicles ( $\sim 40-50 \mathrm{~nm}$ ). Labeled vesicles are tracked with fluorescence microscopy using fluorescence imaging with one-nanometer accuracy (FIONA), stimulated emission depletion (STED) microscopy, fluorescence correlation spectroscopy (FCS), or evanescent wave microscopy. Fluorescence recovery after photobleaching (FRAP) can be combined with these visualization techniques to explore the mobility of vesicles between regions. In addition, ultrastructure of probe-loaded vesicles can be examined by photoconversion of FM dye, use of quantum dots that have an electrondense core, or horseradish peroxidase (HRP). 
$\mathrm{P}_{\mathrm{r}}$ and synaptic strength. Additionally, changes in $N_{\text {RRP }}$ that result from molecular perturbations in presynaptic or vesicular proteins have provided insight into their normal functional role in vesicle fusion (Pang and Südhof 2010).

In general, assessing $N_{\text {RRP }}$ requires (1) a stimulus strong enough to empty the RRP; (2) an assay of presynaptic output (Box 1); and (3) an estimate of the extent to which concurrent refilling of the RRP had offset its stimulus-dependent depletion (Wesseling and Lo 2002; Ruiz et al. 2011).

The choice of stimulation and assay vary widely by system (Rizzoli and Betz 2005), sometimes yielding conflicting interpretations even within the same neuronal preparation (Lou et al. 2005, 2008; Moulder and Mennerick 2005; Stevens and Williams 2007). When HFS is used, differences in $N_{\text {RRP }}$ estimates often arise depending on whether replenishment is deemed to begin at its steady-state rate at the onset of stimulation (Moulder and Mennerick 2005), or to increase to the final rate with a firstorder exponential (Stevens and Williams 2007) or sigmoid (Ruiz et al. 2011) time course. It is likely that proper estimates require careful consideration of the $\mathrm{Ca}^{2+}$ dependence of RRP refilling, which predicts dynamic changes during a stimulus (Fig. 2A) (Sakaba and Neher 2001a; Stevens and Williams 2007; Babai et al. 2010).

A useful alternative for determining $N_{\text {RRP }}$ relies on an osmotic challenge, usually an application of normal saline made hypertonic by the addition of $\sim 500 \mathrm{mOsm} / \mathrm{L}$ sucrose. Although this hypertonic sucrose strategy dates back 60 years (Fatt and Katz 1952), its precise mechanism is incompletely understood. However, cross-depletion analysis shows that both APs and hypertonic sucrose access and deplete an overlapping RRP (Fig. 2B) (Rosenmund and Stevens 1996). Importantly, the response to hypertonic sucrose is calcium independent, being insensitive to loading nerve terminals with strong $\mathrm{Ca}^{2+}$ buffers (Rosenmund and Stevens 1996), and to genetic deletion of synaptotagmin I, the primary calcium sensor for AP-synchronized release in hippocampal terminals (Geppert et al. 1994). By bypassing AP generation, $\mathrm{Ca}^{2+}$ elevation, and calcium-triggered fusion, hypertonic sucrose offers the chance to directly probe downstream aspects of vesicle fusion and to dissociate $\mathrm{Ca}^{2+}$-dependent processes from $\mathrm{Ca}^{2+}$-independent ones that specifically alter the number of release-ready vesicles (Geppert et al. 1994; Reim et al. 2001).

Regulation of $\mathrm{N}_{R R P}$. The capacity of the RRP is generally thought to be limited but appears to scale with the number of TRP vesicles (Murthy and Stevens 1999; Waters and Smith 2002) and overall synapse size (Welzel et al. 2011). A possible limiting factor is the overall area of the AZ where release can occur (Schikorski and Stevens 1997; Ruiz et al. 2011; Welzel et al. 2011). $N_{\text {RRP }}$ at individual synapses generally remains unchanged when measured at sufficiently long intervals (Stevens and Wesseling 1998; Murthy and Stevens 1999); however, $N_{\text {RRP }}$ can be increased by pharmacological activation of protein kinase $\mathrm{C}$ in hippocampal and calyceal terminals (Stevens and Sullivan 1998; Waters and Smith 2000; Fioravante et al. 2011). Interestingly, this occurs primarily at synapses with a small proportion of RRP vesicles, consistent with a ceiling on $N_{\text {RRP }}$ that restricts increases at synapses already at maximal RRP capacity (Waters and Smith 2002).

\section{Recycling Pool (RP)}

The size of the RP is often inferred as the difference between $N_{\text {TRP }}$ and $N_{\text {RRP }}$, using the methods previously described. RP size scales with $N_{\text {TRP }}$ and is typically approximately three times $N_{\text {RRP }}$ at hippocampal synapses (Murthy and Stevens 1999). RP vesicles repopulate vacancies within the RRP and thus require additional transitions, which are often rate-limiting during persistent activity, to become release ready. Consequently, the kinetics of the RP to RRP transition impacts neurotransmission, particularly late during a bout of activity, and offers a potential control point for regulating release efficacy.

Indeed, the time constant of RRP replenishment at rest, measured with a pair of depletion stimuli variably spaced in time, is on the order of several seconds $(\sim 5-10 \mathrm{sec}$ at room temperature) in hippocampal and retinal bipolar synapses (von Gersdorff and Matthews 1997; 
Readily releasable pool and recycling pool vesicles

A

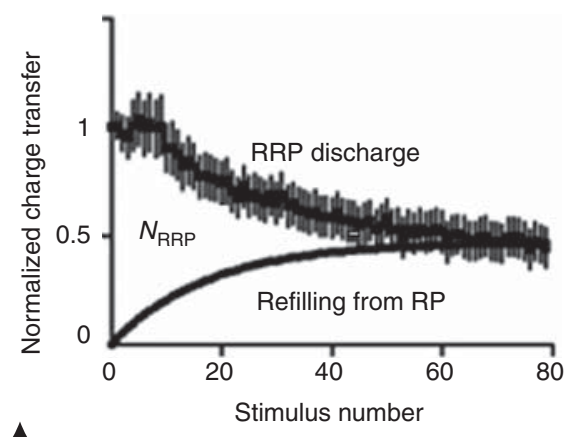

B

\author{
Sucrose $500 \mathrm{~mm}$
}

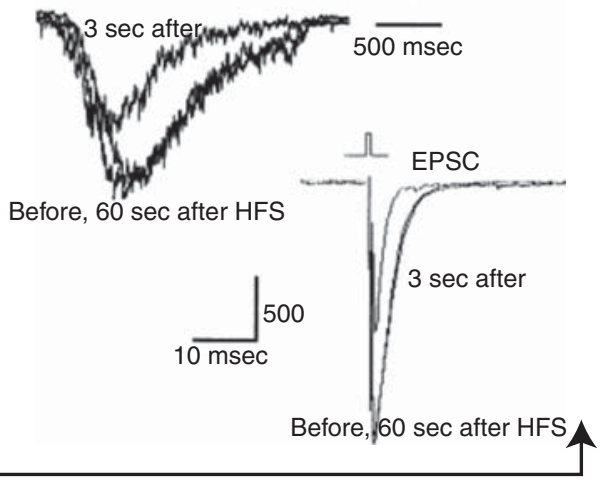

Total recycling pool and resting pool vesicles
C

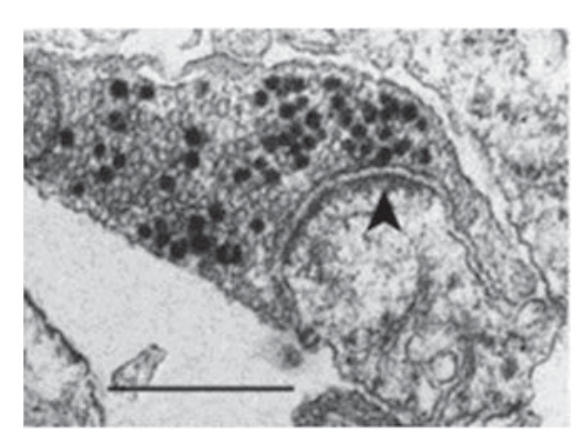

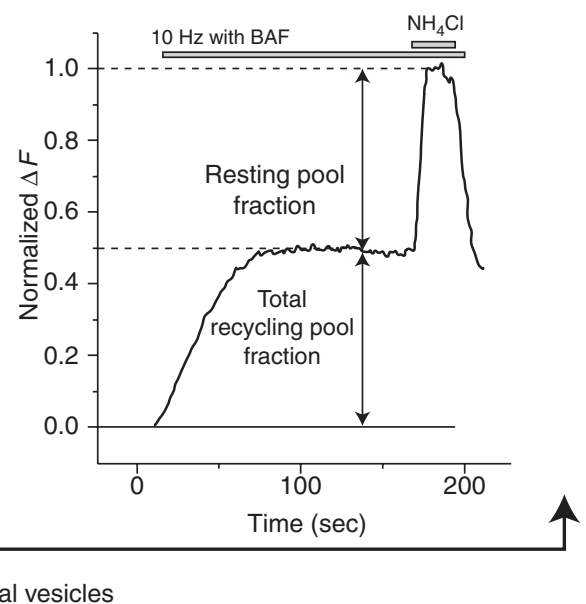

Figure 2. Summary of functional characterization of vesicle pools. (A) Analysis of the action potential (AP) responses from Figure 1B (left panel) indicates the normalized charge transferred per $50 \mathrm{msec}$ time window (interstimulus interval) declines, reflecting a discharge and depletion of readily releasable pool (RRP) vesicles. Note that applying the charge integral and not simply peak amplitude captures synchronous and asynchronous release. Refilling of the RRP from the RP is approximated as a first-order exponential process. RRP size $\left(N_{\mathrm{RRP}}\right)$ is proportional to the total charge integrated over the stimulus duration less that resulting from the refilling process (area between the two curves) (Stevens and Williams 2007). (B) Cross-depletion with high-frequency stimulation (HFS) (100 APs at $20 \mathrm{~Hz}$ ) reveals that both hypertonic sucrose and AP challenges access the same RRP vesicles (Rosenmund and Stevens 1996). (C) Left panel: Example of photoconverted hippocampal terminal after loading with FM1-43 using $20 \mathrm{~Hz}, 60 \mathrm{sec}$ stimulation with an additional $60 \mathrm{sec}$ rest for residual endocytic activity poststimulus. The aim was to label the total recycling pool TRP. Approximately $39 \%$ of vesicles recycled and thus contained electron-dense puncta (dark vesicle lumen), with some in close proximity to the active zone (arrowhead) and others intermixed within the greater bouton area. Scale bar, $0.5 \mu \mathrm{m}$ (Harata et al. 2001b). (Right panel) $10 \mathrm{~Hz}$ stimulation of hippocampal neurons expressing a pHluorin-tagged vesicular protein in the presence of proton-pump inhibitor bafilomycin reveals the TRP. Ammonium chloride pulse at the end of the stimulus neutralizes the remaining pHluorin constructs in acidic compartments, thereby unmasking nonrecycling vesicles in the resting pool (Kim and Ryan 2010). (Panel $A$ is from Stevens and Williams 2007; reprinted, with permission, from the American Physiological Society (C) 2007; Panel B is from Rosenmund and Stevens 1996; reprinted, with permission, from Elsevier (C) 1996; right side of Panel $C$ is from Kim and Ryan 2010; reprinted, with permission, from Elsevier (C) 2010.) 
Stevens and Wesseling 1998) but appears to be heavily modulated. Activity causes a $\mathrm{Ca}^{2+}$-dependent speeding of replenishment, reaching a maximal level within a couple of seconds of HFS (Fig. 2A) (Smith et al. 1998; Stevens and Wesseling 1998; Wang and Kaczmarek 1998; Gomis et al. 1999), providing a mechanism to resupply RRP vesicles at highly active synapses. Replenishment is further enhanced by warming to physiological temperature (Pyott and Rosenmund 2002) and protein kinase C stimulation (Stevens and Sullivan 1998).

A deeper form of short-term depression? During extended stimuli that mobilize RP vesicles, a deep, long-lived depression in neurotransmission has been reported in multiple synaptic preparations (Abbott et al. 1997; von Gersdorff and Matthews 1997; Stevens and Wesseling 1999b). Contrary to RRP depletion, which typically requires $<30 \mathrm{sec}$ for recovery (Stevens and Wesseling 1998), this deeper state persists for several minutes and has been suggested to represent the rate-limiting recycling of depleted RP vesicles (Liu and Tsien 1995). Alternatively, it may result from the rate-limiting clearance of fused vesicle components that accumulate near the AZ during heavy activity (Stevens and Wesseling 1999b; Garcia-Perez et al. 2008). These could occlude potential release sites, limiting the supply of RP vesicles to the RRP in what has been termed "supply-rate depression" (Garcia-Perez et al. 2008). Consistent with this, the endocytosis that accompanies such heavy use involves large invaginations and the formation of endosome-like structures at the NMJ to recapture bulk vesicular membrane all at once. Finally, this depression could be accounted for by an alternative arrangement of RRP and RP vesicles that predicts changes in the nature of replenishment during persistent stimulation (Gabriel et al. 2011).

\section{Resting Pool $\left(\mathrm{R}_{\mathrm{t}} \mathrm{P}\right)$}

The $\mathrm{R}_{\mathrm{t}} \mathrm{P}$, introduced earlier in this article, is defined as a set of vesicles that remain unreleased even after prolonged stimulation that causes a saturating degree of vesicular turnover (Harata et al. 2001b; Li et al. 2005). Assessment of $\mathrm{R}_{\mathrm{t}} \mathrm{P}$ size often relies on detection of vesicles unable to release genetically encoded pHluorin probes (Box 1) as assayed by fluorescence microscopy (Poskanzer and Davis 2004; Fernandez-Alfonso and Ryan 2008) or uptake exogenous probes as assayed by EM of electron-dense QD cores (Zhang et al. 2007) or by-products produced by photoconversion of FM dye (Fig. 2B) (Harata et al. 2001b). Typical estimates of average $\mathrm{R}_{t} \mathrm{P}$ size range from $\sim 50 \%-85 \%$ of all vesicles ( $\mathrm{Ha}-$ rata et al. 2001b; Fernandez-Alfonso and Ryan 2008; but see Ikeda and Bekkers 2009). A similar nonrecycling pool has been suggested at the calyx of Held (de Lange et al. 2003), and NMJs of Drosophila (Poskanzer and Davis 2004) and mouse (Wyatt and Balice-Gordon 2008). Even in terminals said to be devoid of an $\mathrm{R}_{\mathrm{t}} \mathrm{P}, \sim 15 \%$ of vesicles are unlabeled in ultrastructural images of photoconverted boutons maximally loaded with FM dye (Richards et al. 2003).

Given the paucity of SVs at central terminals it is surprising that so many vesicles appear in the $\mathrm{R}_{\mathrm{t}} \mathrm{P}$. A partial rationale is that a relatively small number of vesicles suffice to maintain neurotransmission even without $\mathrm{R}_{\mathrm{t}} \mathrm{P}$ mobilization (Murthy and Stevens 1998; Pyle et al. 2000; Richards et al. 2003; Denker et al. 2011a). An additional feature is that $\mathrm{R}_{t} \mathrm{P}$ vesicles are recruited by intracellular signaling pathways. For example, at the Drosophila NMJ, the vesicles most reluctant to release can be recruited to the RRP using a protein kinase A pathway involving filamentous actin (Kuromi and Kidokoro 2005). In hippocampal terminals, $\mathrm{R}_{\mathrm{t}} \mathrm{P}$ mobilization can be achieved by inhibition of cyclin-dependent kinase 5 (CDK5) (Kim and Ryan 2010). Loss of presynaptic CDK5 may occur in response to prolonged neuronal silencing (Kim and Ryan 2010), and contribute to homeostatic scaling of presynaptic release (Murthy et al. 2001; Thiagarajan et al. 2005). Restoration of the $\mathrm{R}_{\mathrm{t}} \mathrm{P}$ involves an opposing action by the calcium-dependent phosphatase calcineurin. Thus, opposing effects of phosphorylation-dephosphorylation may tilt the balance between recycling and nonrecycling vesicles to adaptively alter synaptic strength without varying total vesicle number or bouton size (Fig. 3) (Ratnayaka et al. 2012). 


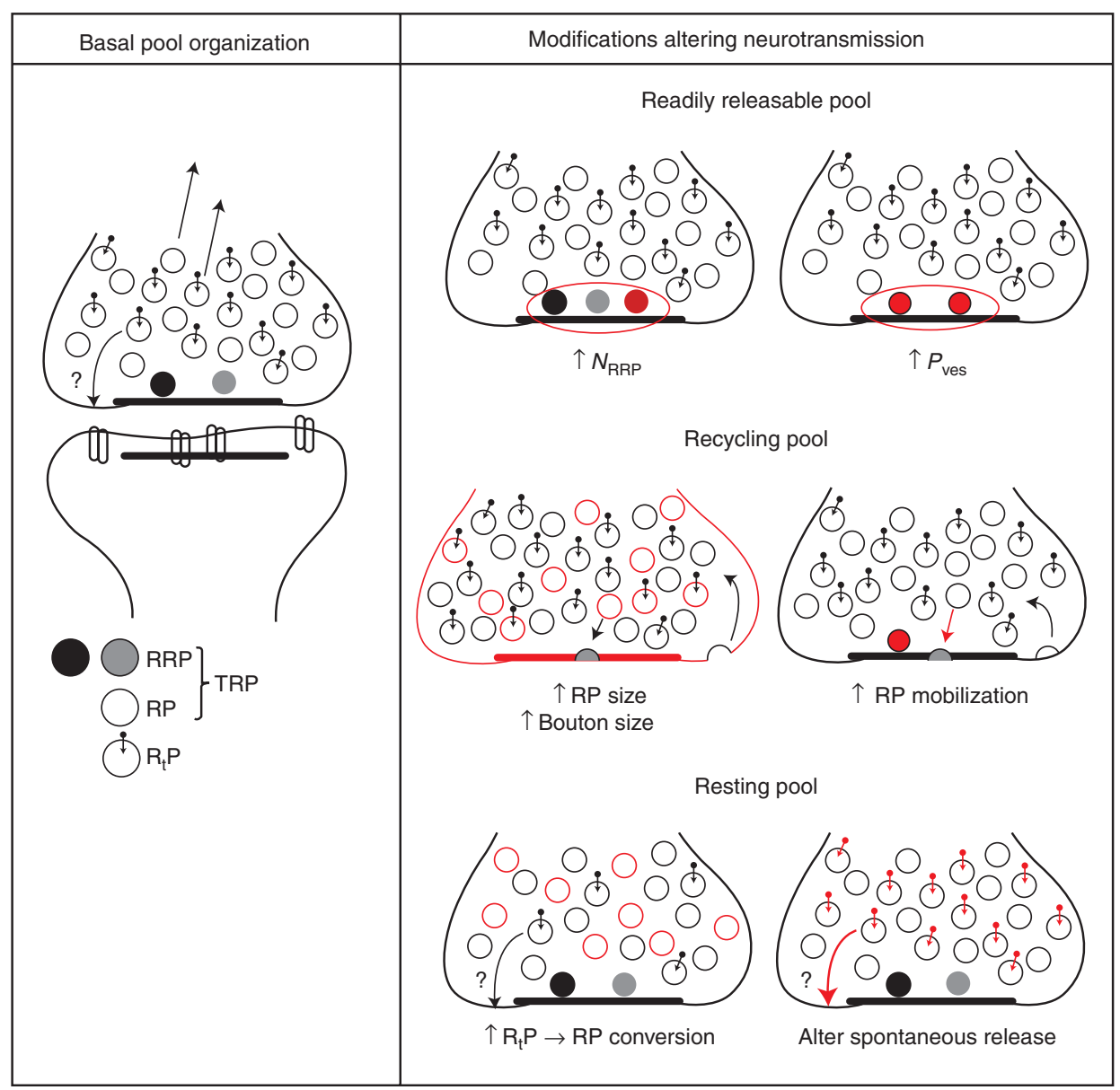

Figure 3. Simplified overview of vesicle pool function and regulation. Left column: Vesicles in RRP are presumed to be in close proximity to active zone for highest $P_{\text {ves }}$ at the bouton and rapid fusion. $\mathrm{RP}$ and $\mathrm{R}_{\mathrm{t}} \mathrm{P}$ vesicles are interspersed within vesicle cluster. Both contribute to the vesicle superpool (arrows leaving bouton). $\mathrm{R}_{\mathrm{t}} \mathrm{P}$ vesicles are distinguished by molecular labels (Hua et al. 2011; Ramirez et al. 2012) and possibly contribute to spontaneous release at sites outside AZ (Zenisek 2008). Shading of RRP vesicles reflects potential RRP heterogeneity. The number of vesicles depicted within the bouton is scaled down by a factor of 5 for easy visualization. Right column: Modifications to vesicle pool number or properties are marked in red when compared to basal state. Each modification contributes to shaping neurotransmission and short-term plasticity (see text for further details). For RRP, the number of vesicles $\left(N_{\mathrm{RRP}}\right)$ or their fusion probability $\left(P_{\text {ves }}\right)$ may change. For RP, increases in bouton size can accommodate more RP (and $\mathrm{R}_{\mathrm{t}} \mathrm{P}$ ) vesicles and increase active zone length (which could possibly enhance RRP capacity) (Welzel et al. 2011). Additionally, calcium or protein kinase C activation can accelerate RP mobilization, mitigating RRP depletion. For $\mathrm{R}_{\mathrm{t}} \mathrm{P}$, inhibition of CDK5 recruits vesicles to the total recycling pool (TRP) (Kim and Ryan 2010) and modification of a proposed molecular label can alter the frequency of spontaneous release events (Ramirez et al. 2012).

$\mathrm{R}_{\mathrm{t}} \mathrm{P}$ vesicles may have additional physiologically relevant functions as suggested by recent evidence. First, they can be dynamically exchanged between boutons as members of a vesicle "superpool" (Fernandez-Alfonso and Ryan
2008). Second, they might serve as a buffer for the trapping and activity-dependent supply of proteins used in vesicle recycling (Denker et al. $2011 b$ ). Third, the $R_{t} P$ may be a source of vesicles released during spontaneous miniature 
events ("minis"), determined using various crossdepletion strategies and spectrally separable fluorescent probes to monitor vesicle fusion during spontaneous or evoked activity. Kavalali and colleagues have advanced a model wherein spontaneous release signals to a distinct complement of postsynaptic receptors (Atasoy et al. 2008; Sara et al. 2011) and is derived from a limited pool of vesicles reluctant to fuse during evoked activity (Sara et al. 2005; Chung et al. 2010), formally identified as part of the $\mathrm{R}_{\mathrm{t}} \mathrm{P}$ by Fredj and Burrone (Fredj and Burrone 2009), which are molecularly defined by the RSNARE protein Vtila (Vps-10p-tail-interactor1a) (Ramirez et al. 2012). However, using very similar methods, Klingauf and colleagues find that spontaneous and evoked release share an overlapping set of vesicles (Groemer and Klingauf 2007; Hua et al. 2010) and in a broad set of experiments in multiple preparations, Rizzoli and colleagues reinforce this idea (Wilhelm et al. 2010). The lack of consensus on this subject will undoubtedly make it a target of continued study.

\section{NEW CONCEPTS IN UNDERSTANDING THE ORGANIZATION OF VESICLE POOLS}

Beyond the pools discussed thus far, the general concept of vesicle pools has been further expanded by additional studies of vesicle dynamics. These have revealed both fine substructure and global superstructure relative to the canonical pools.

\section{Subdivisions within the RRP}

As if distinctions between the RRP and RP were not enough, the RRP itself is likely more heterogeneous than originally appreciated. Under basal physiological conditions, an incoming AP appears to be able to trigger transmitter release from only a small subset of vesicles that are "preprimed" (Hanse and Gustafsson 2001b) or "rapidly releasing" (Heinemann et al. 1994; Wu and Borst 1999; Schneggenburger et al. 2002). Depletion of this preprimed subpool, part of the RRP, has been detected kinetically, as a form of depression operating on a millisecond timescale (Dobrunz et al. 1997). Compared to this privileged subpool, the remainder of the RRP is relatively reluctant to release. This phenomenon appears to be quite general, having been reported for the calyx of Held ( $\mathrm{Wu}$ and Borst 1999; Sakaba and Neher 2001b) and retinal bipolar neurons (Burrone and Lagnado 2000). Typical estimates suggest that $\sim 10 \%-$ $20 \%$ of the RRP is immediately available for release (Moulder and Mennerick 2005), or $\sim 1$ vesicle for hippocampal terminals. This lines up with observations that hippocampal synapses typically contain a single active zone, possibly corresponding to $\sim 1$ release site (Schikorski and Stevens 1997), and discharge at most one vesicle per AP per synapse (an approximate "one-vesicle rule") (Stevens and Wang 1995; Hanse and Gustafsson 2001b). The preprimed subpool has been interpreted in various ways. It might reflect a limit on the number of release sites available for fusion, such that relatively reluctant RRP vesicles must undergo a final, albeit fast, transition to full competence for fusion (Hanse and Gustafsson 2001b). It could also be a consequence of use-dependent changes in the release site(s) that make other RRP vesicles more reluctant to fuse (Dobrunz et al. 1997; Stevens and Wesseling 1999a). Finally, as suggested for the calyx of Held, it may reflect a favorable positioning relative to $\mathrm{Ca}^{2+}$ channels or inherent differences in $\mathrm{Ca}^{2+}$ sensitivity $(\mathrm{Ne}-$ her and Sakaba 2008). Whatever the mechanism, a preprimed subpool would have important implications for activity-dependent changes in $\mathrm{P}_{\mathrm{r}}$ (Stevens and Wesseling 1999a; Hanse and Gustafsson 2001a). Changes in the size of the subpool or the $P_{\text {ves }}$ of its members could have a major impact on synaptic efficacy (Fig. 3) (Stevens and Wesseling 1999a; Lee et al. 2010).

\section{Vesicle Superpool and Interterminal Exchange}

The underlying premise of canonical pools, that boutons operate independently, is undoubtedly an oversimplification. Growing evidence points to a vesicle superpool that transits rapidly between synapses, as seen in neuronal culture (Krueger et al. 2003), native brain tissue (Staras 
et al. 2010), and in vivo (Herzog et al. 2011). Superpool vesicles depart their original bouton and travel along axons to functionally integrate into new terminals as far as $30 \mu \mathrm{m}$ away (Staras et al. 2010). Dynamic imaging of fluorescently labeled vesicles suggests that the superpool is derived from both $\mathrm{RP}$ and $\mathrm{R}_{\mathrm{t}} \mathrm{P}$ vesicles (Fig. 3) (Darcy et al. 2006; Fernandez-Alfonso and Ryan 2008; Kamin et al. 2010). The turnover rate has been estimated as $\sim 4 \%$ of all vesicles per minute (Staras et al. 2010) and intra-axonal motion has been described as diffusive mobility (Westphal et al. 2008), actin turnover dependent (Darcy et al. 2006), or dependent on microtubulebased motors (Westphal et al. 2008). The signals and molecules that regulate vesicle reallocation among synapses are unclear, but may include presynaptic activity (Fisher-Lavie et al. 2011) and brain-derived neurotrophic factor (BDNF), signaling through its receptor TrkB (Staras et al. 2010). Interbouton exchange of vesicles could operate alongside sharing of presynaptic molecules (Kalla et al. 2006; Tsuriel et al. 2009; Ribrault et al. 2011) to provide a mechanism for synapse-specific changes in synaptic strength. Together, both factors may support synaptic remodeling events that underlie certain forms of plasticity and homeostasis (Matz et al. 2010; Herzog et al. 2011). This may partially recapitulate synapse formation in developing hippocampal neurons, which relies on intra-axonal mobility of vesicles and AZ proteins (Kraszewski et al. 1995; Ahmari et al. 2000).

\section{FUNDAMENTAL QUESTIONS THAT REMAIN UNANSWERED}

Vesicles display a greater complexity of function and regulation than is discussed here. Nevertheless we have highlighted some key properties of different vesicle pools. For signaling molecules like protein kinase $\mathrm{C}$ (PKC) and CDK5, which alter vesicle pools and dynamics, the primary effectors of this action, be they vesicular proteins, presynaptic proteins, or elements of the cytoskeleton, are intently sought after. Elegant studies that have linked $\mathrm{Ca}^{2+}$ accumulation during presynaptic activity to the function of the priming molecule Munc-13 and subsequent enhancement of vesicle fusion probability exemplify the type of understanding possible (Shin et al. 2010). Clarification of the signals and effector proteins that impinge on vesicle dynamics will provide a more complete cell biological framework for understanding how transmitter release is regulated by synaptic activity. Further understanding will also require renewed focus on some of the more complex questions below.

To what extent are SV biochemically homogeneous? The pioneering study of Jahn and colleagues (Takamori et al. 2006) made the reasonable first approximation that all SV can be treated as biochemically uniform, a simplification also implicit in biophysical modeling of vesicle trafficking. Future studies must reckon with the possibility that molecular heterogeneity exists, and that vesicles bearing distinct biochemical fingerprints, in either the number or subtype of vesicle proteins, differ in their functional properties. If this is the case, it will be important to ascertain whether vesicle identity is preserved after a cycle of full collapse fusion and retrieval. Already, experiments suggest that certain vesicle proteins can remain clustered post fusion (Opazo et al. 2010) and undergo concerted retrieval, suggesting that the reconstructed vesicle may retain certain functional features of its predecessor, such as fusion probability. Indeed, $\mathrm{R}_{\mathrm{t}} \mathrm{P}$ vesicles appear to be distinguished by the presence of the v-SNARE protein vAMP7 (vesicle-associated membrane protein 7) (Hua et al. 2011) and vesicles that support spontaneous minis recycle continuously along with the molecular identifier Vtila (Ramirez et al. 2012).

Do vesicles traffic by queuing and if so, is it a single queue? One possible interpretation of the cell biology of vesicle cycling described by Heuser and Reese (1981) is that vesicles follow a stereotyped route following endocytosis. More recent work has outlined multiple parallel routes that can be traversed by the newly internalized vesicle before it undergoes fusion once again (Fesce et al. 1994; Stevens and Williams 2000; Murthy and De Camilli 2003). The topology of these pathways, and the key temporal bottlenecks, are incompletely understood (Fernandez-Alfonso and Ryan 2006). A related 
question is whether vesicles undergo random mixing or follow a nonrandom pecking order from one round of fusion to the next (Park et al. 2012).

What does refilling a pool mean? The term pool implies a vessel of finite capacity, like a bathtub, that is separately drained and refilled and can range from empty to completely filled. Because this pool must have an existence independent of its contents, physical location is an appealing way to conceptualize it. For example, the RRP is conventionally thought of as delimited by docking sites on the active zone. If, however, RRP vesicles were made up of small groups of vesicles, strung together by synapsin-dependent interactions (Gabriel et al. 2011), the limit on pool capacity and the nature of its refilling would be very different, even if the broad implications for STP were basically similar. In this unconventional view, the basal location of the RRP would not be within a vesicle's breadth of the site of fusion but up to a few vesicle diameters away (Park et al. 2012).

Answering these questions will call for new experiments to track the spatiotemporal dynamics of single vesicles.

\section{CONCLUDING REMARKS}

The idea of vesicle pools has a long history and great ongoing relevance to the cell biology of nerve terminals, to the underpinnings of synaptic plasticity, and to the workings of brain networks. Understanding the nature of vesicle pools and their dynamics is as intellectually challenging and experimentally thorny as any of the topics in this collection. Despite multiple controversies, prospects are bright for a melding of insights from ultrastructural, biophysical, and molecular approaches. In combination, these may bring concepts of vesicle pools to a new level of clarity.

\section{ACKNOWLEDGMENTS}

Work by A.A.A. and R.W.T. on presynaptic vesicles is supported by grants from the National Institute of Mental Health, the Burnett Family Fund (R.W.T.), the Mathers Foundation (R.W.T.), the Stanford Medical Scientist Train- ing Program, and the Paul and Daisy Soros Fellowship (A.A.A.).

\section{REFERENCES}

${ }^{*}$ Reference is also in this collection.

Abbott LF, Regehr WG. 2004. Synaptic computation. Nature 431: 796-803.

Abbott LF, Varela JA, Sen K, Nelson SB. 1997. Synaptic depression and cortical gain control. Science 275: 220224.

Ahmari SE, Buchanan J, Smith SJ. 2000. Assembly of presynaptic active zones from cytoplasmic transport packets. Nat Neurosci 3: 445-451.

Allen C, Stevens CF. 1994. An evaluation of causes for unreliability of synaptic transmission. Proc Natl Acad Sci 91: 10380-10383.

Armitage BA, Siegelbaum SA. 1998. Presynaptic induction and expression of homosynaptic depression at Aplysia sensorimotor neuron synapses. J Neurosci 18: 8770 8779.

Atasoy D, Ertunc M, Moulder KL, Blackwell J, Chung C, Su J, Kavalali ET. 2008. Spontaneous and evoked glutamate release activates two populations of NMDA receptors with limited overlap. J Neurosci 28: 10151-10166.

Babai N, Bartoletti TM, Thoreson WB. 2010. Calcium regulates vesicle replenishment at the cone ribbon synapse. J Neurosci 30: 15866-15877.

Bielefeldt K, Jackson MB. 1993. A calcium-activated potassium channel causes frequency-dependent action-potential failures in a mammalian nerve terminal. J Neurophysiol 70: $284-298$.

Birks R, Macintosh FC. 1961. Acetylcholine metabolism of a sympathetic ganglion. Can J Biochem Phys 39: 787.

Bittner GD, Kennedy D. 1970. Quantitative aspects of transmitter release. J Cell Biol 47: 585-592.

* Blakely RD, Edwards RH. 2012. Vesicular and plasma membrane transporters for neurotransmitters. Cold Spring Harb Perspect Biol 4: a005595.

Burrone J, Lagnado L. 2000. Synaptic depression and the kinetics of exocytosis in retinal bipolar cells. J Neurosci 20: $568-578$.

Chung C, Barylko B, Leitz J, Liu X, Kavalali ET. 2010. Acute dynamin inhibition dissects synaptic vesicle recycling pathways that drive spontaneous and evoked neurotransmission. J Neurosci 30: 1363-1376.

Darcy KJ, Staras K, Collinson LM, Goda Y. 2006. Constitutive sharing of recycling synaptic vesicles between presynaptic boutons. Nat Neurosci 9: 315-321.

Dekay JG, Chang TC, Mills N, Speed HE, Dobrunz LE. 2006. Responses of excitatory hippocampal synapses to natural stimulus patterns reveal a decrease in short-term facilitation and increase in short-term depression during postnatal development. Hippocampus 16: 66-79.

de Lange RP, de Roos AD, Borst JG. 2003. Two modes of vesicle recycling in the rat calyx of Held. J Neurosci 23: 10164-10173.

Del Castillo J, Katz B. 1954. Quantal components of the endplate potential. J Physiol 124: 560-573. 
Del Castillo J, Katz B. 1956. Biophysical aspects of neuromuscular transmission. Prog. Biophys. Biophys. Chem. 6: $121-170$.

Denker A, Bethani I, Krohnert K, Korber C, Horstmann H, Wilhelm BG, Barysch SV, Kuner T, Neher E, Rizzoli SO. 2011a. A small pool of vesicles maintains synaptic activity in vivo. Proc Natl Acad Sci 108: $17177-17182$.

Denker A, Krohnert K, Buckers J, Neher E, Rizzoli SO. 2011b. The reserve pool of synaptic vesicles acts as a buffer for proteins involved in synaptic vesicle recycling. Proc Natl Acad Sci 108: 17183-17188.

De Robertis ED, Bennett HS. 1955. Some features of the submicroscopic morphology of synapses in frog and earthworm. J Biophys Biochem Cytol 1: 47-58.

Dobrunz LE, Stevens CF. 1997. Heterogeneity of release probability, facilitation, and depletion at central synapses. Neuron 18: 995-1008.

Dobrunz LE, Stevens CF. 1999. Response of hippocampal synapses to natural stimulation patterns. Neuron 22: 157-166.

Dobrunz LE, Huang EP, Stevens CF. 1997. Very short-term plasticity in hippocampal synapses. Proc Natl Acad Sci 94: 14843-14847.

Elmqvist D, Quastel DM. 1965. A quantitative study of endplate potentials in isolated human muscle. J Physiol 178: 505-529.

Fatt P, Katz B. 1952. Spontaneous subthreshold activity at motor nerve endings. J Physiol 117: 109-128.

Fenton AA, Muller RU. 1998. Place cell discharge is extremely variable during individual passes of the rat through the firing field. Proc Natl Acad Sci 95: 3182-3187.

Fernandez-Alfonso T, Ryan TA. 2006. The efficiency of the synaptic vesicle cycle at central nervous system synapses. Trends Cell Biol 16: 413-420.

Fernandez-Alfonso T, Ryan TA. 2008. A heterogeneous "resting" pool of synaptic vesicles that is dynamically interchanged across boutons in mammalian CNS synapses. Brain Cell Biol 36: 87-100.

Fesce R, Grohovaz F, Valtorta F, Meldolesi F. 1994. Neurotransmitter release: fusion or "kiss-and-run?" Trends Cell Biol 4: 1-4.

Fioravante D, Chu Y, Myoga MH, Leitges M, Regehr WG. 2011. Calcium-dependent isoforms of protein kinase $C$ mediate posttetanic potentiation at the calyx of Held. Neuron 70: 1005-1019.

Fisher-Lavie A, Zeidan A, Stern M, Garner CC, Ziv NE. 2011. Use dependence of presynaptic tenacity. J Neurosci 31: $16770-16780$.

Fredj NB, Burrone J. 2009. A resting pool of vesicles is responsible for spontaneous vesicle fusion at the synapse. Nat Neurosci 12: 751-758.

Gabriel T, Garcia-Perez E, Mahfooz K, Goni J, MartinezTurrillas R, Perez-Otano I, Lo DC, Wesseling JF. 2011. A new kinetic framework for synaptic vesicle trafficking tested in synapsin knock-outs. J Neurosci 31: 1156311577.

Garcia-Perez E, Lo DC, Wesseling JF. 2008. Kinetic isolation of a slowly recovering component of short-term depression during exhaustive use at excitatory hippocampal synapses. J Neurophysiol 100: 781-795.
Geppert M, Goda Y, Hammer RE, Li C, Rosahl TW, Stevens CF, Südhof TC. 1994. Synaptotagmin I: A major $\mathrm{Ca}^{2+}$ sensor for transmitter release at a central synapse. Cell 79: 717-727.

Goda Y, Stevens CF. 1998. Readily releasable pool size changes associated with long term depression. Proc Natl Acad Sci 95: 1283-1288.

Gomis A, Burrone J, Lagnado L. 1999. Two actions of calcium regulate the supply of releasable vesicles at the ribbon synapse of retinal bipolar cells. J Neurosci 19: 6309-6317.

Groemer TW, Klingauf J. 2007. Synaptic vesicles recycling spontaneously and during activity belong to the same vesicle pool. Nat Neurosci 10: 145-147.

Hallermann S, Pawlu C, Jonas P, Heckmann M. 2003. A large pool of releasable vesicles in a cortical glutamatergic synapse. Proc Natl Acad Sci 100: 8975-8980.

Hallermann S, Fejtova A, Schmidt H, Weyhersmuller A, Silver RA, Gundelfinger ED, Eilers J. 2010. Bassoon speeds vesicle reloading at a central excitatory synapse. Neuron 68: 710-723.

Hanse E, Gustafsson B. 2001a. Factors explaining heterogeneity in short-term synaptic dynamics of hippocampal glutamatergic synapses in the neonatal rat. J Physiol 537: $141-149$.

Hanse E, Gustafsson B. 2001b. Vesicle release probability and pre-primed pool at glutamatergic synapses in area CA1 of the rat neonatal hippocampus. J Physiol 531: 481-493.

Harata N, Pyle JL, Aravanis AM, Mozhayeva M, Kavalali ET, Tsien RW. 2001a. Limited numbers of recycling vesicles in small CNS nerve terminals: Implications for neural signaling and vesicular cycling. Trends Neurosci 24: 637-643.

Harata N, Ryan TA, Smith SJ, Buchanan J, Tsien RW. 2001b. Visualizing recycling synaptic vesicles in hippocampal neurons by FM 1-43 photoconversion. Proc Natl Acad Sci 98: $12748-12753$.

Harata NC, Aravanis AM, Tsien RW. 2006. Kiss-and-run and full-collapse fusion as modes of exo-endocytosis in neurosecretion. J Neurochem 97: 1546-1570.

Harris KM, Sultan P. 1995. Variation in the number, location and size of synaptic vesicles provides an anatomical basis for the nonuniform probability of release at hippocampal CA1 synapses. Neuropharmacology 34: 1387-1395.

Heinemann C, Chow RH, Neher E, Zucker RS. 1994. Kinetics of the secretory response in bovine chromaffin cells following flash photolysis of caged $\mathrm{Ca}^{2+}$. Biophys J 67: 2546-2557.

Herzog E, Nadrigny F, Silm K, Biesemann C, Helling I, Bersot T, Steffens H, Schwartzmann R, Nagerl UV, El Mestikawy S, et al. 2011. In vivo imaging of intersynaptic vesicle exchange using VGLUT1 Venus knock-in mice. J Neurosci 31: 15544-15559.

Hessler NA, Shirke AM, Malinow R. 1993. The probability of transmitter release at a mammalian central synapse. Nature 366: 569-572.

Heuser JE, Reese TS. 1981. Structural changes after transmitter release at the frog neuromuscular junction. J Cell Biol 88: 564-580. 
A.A. Alabi and R.W. Tsien

Hodgkin AL, Huxley AF. 1952. A quantitative description of membrane current and its application to conduction and excitation in nerve. J Physiol 117: 500-544.

Hua Y, Sinha R, Martineau M, Kahms M, Klingauf J. 2010. A common origin of synaptic vesicles undergoing evoked and spontaneous fusion. Nat Neurosci 13: 1451-1453.

Hua Z, Leal-Ortiz S, Foss SM, Waites CL, Garner CC, Voglmaier SM, Edwards RH. 2011. v-SNARE composition distinguishes synaptic vesicle pools. Neuron 71: 474-487.

Ikeda K, Bekkers JM. 2009. Counting the number of releasable synaptic vesicles in a presynaptic terminal. Proc Nat Acad Sci 106: 2945-2950.

Kalla S, Stern M, Basu J, Varoqueaux F, Reim K, Rosenmund C, Ziv NE, Brose N. 2006. Molecular dynamics of a presynaptic active zone protein studied in Munc13-1-enhanced yellow fluorescent protein knock-in mutant mice. J Neurosci 26: 13054-13066.

Kamin D, Lauterbach MA, Westphal V, Keller J, Schonle A, Hell SW, Rizzoli SO. 2010. High- and low-mobility stages in the synaptic vesicle cycle. Biophys J 99: 675-684.

Kim SH, Ryan TA. 2010. CDK5 serves as a major control point in neurotransmitter release. Neuron 67: 797-809.

Kraszewski K, Mundigl O, Daniell L, Verderio C, Matteoli M, De Camilli P. 1995. Synaptic vesicle dynamics in living cultured hippocampal neurons visualized with CY3-conjugated antibodies directed against the lumenal domain of synaptotagmin. J Neurosci 15: 4328-4342.

Kraushaar U, Jonas P. 2000. Efficacy and stability of quantal GABA release at a hippocampal interneuron-principal neuron synapse. J Neurosci 20: 5594-5607.

Krueger SR, Kolar A, Fitzsimonds RM. 2003. The presynaptic release apparatus is functional in the absence of dendritic contact and highly mobile within isolated axons. Neuron 40: 945-957.

Kuromi H, Kidokoro Y. 2005. Exocytosis and endocytosis of synaptic vesicles and functional roles of vesicle pools: Lessons from the Drosophila neuromuscular junction. Neuroscientist 11: 138-147.

Lee JS, Ho WK, Lee SH. 2010. Post-tetanic increase in the fast-releasing synaptic vesicle pool at the expense of the slowly releasing pool. J Gen Physiol 136: 259-272.

Li Z, Burrone J, Tyler WJ, Hartman KN, Albeanu DF, Murthy VN. 2005. Synaptic vesicle recycling studied in transgenic mice expressing synaptopHluorin. Proc Natl Acad Sci 102: 6131-6136.

Liley AW, North KA. 1953. An electrical investigation of effects of repetitive stimulation on mammalian neuromuscular junction. J Neurophysiol 16: 509-527.

Liu G, Tsien RW. 1995. Properties of synaptic transmission at single hippocampal synaptic boutons. Nature 375: 404-408.

Lou X, Scheuss V, Schneggenburger R. 2005. Allosteric modulation of the presynaptic $\mathrm{Ca}^{2+}$ sensor for vesicle fusion. Nature 435: 497-501.

Lou X, Korogod N, Brose N, Schneggenburger R. 2008. Phorbol esters modulate spontaneous and $\mathrm{Ca}^{2+}$-evoked transmitter release via acting on both Munc13 and protein kinase C. J Neurosci 28: 8257-8267.

Lundberg A, Quilisch H. 1953. Presynaptic potentiation and depression of neuromuscular transmission in frog and rat. Acta Physiol Scand Suppl 111: 111-120.
Matz J, Gilyan A, Kolar A, McCarvill T, Krueger SR. 2010. Rapid structural alterations of the active zone lead to sustained changes in neurotransmitter release. Proc Natl Acad Sci 107: 8836-8841.

Miesenbock G, De Angelis DA, Rothman JE. 1998. Visualizing secretion and synaptic transmission with $\mathrm{pH}$-sensitive green fluorescent proteins. Nature 394: 192-195.

Mochida S, Few AP, Scheuer T, Catterall WA. 2008. Regulation of presynaptic $\mathrm{Ca}(\mathrm{V}) 2.1$ channels by $\mathrm{Ca}^{2+}$ sensor proteins mediates short-term synaptic plasticity. Neuron 57: $210-216$.

Moulder KL, Mennerick S. 2005. Reluctant vesicles contribute to the total readily releasable pool in glutamatergic hippocampal neurons. J Neurosci 25: 3842-3850.

Murthy VN, De Camilli P. 2003. Cell biology of the presynaptic terminal. Annu Rev Neurosci 26: 701-728.

Murthy VN, Stevens CF. 1998. Synaptic vesicles retain their identity through the endocytic cycle. Nature 392: $497-$ 501.

Murthy VN, Stevens CF. 1999. Reversal of synaptic vesicle docking at central synapses. Nat Neurosci 2: 503-507.

Murthy VN, Sejnowski TJ, Stevens CF. 1997. Heterogeneous release properties of visualized individual hippocampal synapses. Neuron 18: 599-612.

Murthy VN, Schikorski T, Stevens CF, Zhu Y. 2001. Inactivity produces increases in neurotransmitter release and synapse size. Neuron 32: 673-682.

Neher E. 2008. Multiple roles of calcium ions in the regulation of neurotransmitter release. Neuron 59: 861-872.

Neher E, Sakaba T. 2001. Combining deconvolution and noise analysis for the estimation of transmitter release rates at the calyx of held. J Neurosci 21: 444-461.

Opazo F, Punge A, Buckers J, Hoopmann P, Kastrup L, Hell SW, Rizzoli SO. 2010. Limited intermixing of synaptic vesicle components upon vesicle recycling. Traffic 11: $800-812$.

Otis T, Zhang S, Trussell LO. 1996. Direct measurement of AMPA receptor desensitization induced by glutamatergic synaptic transmission. J Neurosci 16: 7496-7504.

Palade GE. 1954. Electron microscope observations of interneuronal and neuromuscular synapses. Anat Rec 118: 335-336.

Palay SL. 1954. Electron microscope study of the cytoplasm of neurons. Anat Rec 118: 336

Palay SL. 1956. Synapses in the central nervous system. J Biophys Biochem Cytol 2: 193-202.

Pang ZP, Südhof TC. 2010. Cell biology of $\mathrm{Ca}^{2+}$-triggered exocytosis. Curr Opin Cell Biol 22: 496-505.

Park H, Li Y, Tsien RW. 2012. Influence of synaptic vesicle position on release probability and exocytic fusion mode. Science doi: 10.1126/science.1216937.

Poskanzer KE, Davis GW. 2004. Mobilization and fusion of a non-recycling pool of synaptic vesicles under conditions of endocytic blockade. Neuropharmacology 47: 714-723.

Pyle JL, Kavalali ET, Piedras-Renteria ES, Tsien RW. 2000. Rapid reuse of readily releasable pool vesicles at hippocampal synapses. Neuron 28: 221-231.

Pyott SJ, Rosenmund C. 2002. The effects of temperature on vesicular supply and release in autaptic cultures of rat and mouse hippocampal neurons. J Physiol 539: 523-535. 
Ramirez DM, Khvotchev M, Trauterman B, Kavalali ET. 2012. Vtila identifies a vesicle pool that preferentially recycles at rest and maintains spontaneous neurotransmission. Neuron 73: 121-134.

Ratnayaka A, Marra V, Bush D, Burden JJ, Branco T, Staras K. 2012. Recruitment of resting vesicles into recycling pools supports NMDA-receptor dependent synaptic potentiation in cultured hippocampal neurons. J Physiol doi: 10.1113/jphysiol.2011.226688

Reim K, Mansour M, Varoqueaux F, McMahon HT, Südhof TC, Brose N, Rosenmund C. 2001. Complexins regulate a late step in $\mathrm{Ca}^{2+}$-dependent neurotransmitter release. Cell 104: 71-81.

Ribrault C, Reingruber J, Petkovic M, Galli T, Ziv NE, Holcman D, Triller A. 2011. Syntaxin1A lateral diffusion reveals transient and local SNARE interactions. J Neurosci 31: 17590-17602.

Richards DA, Guatimosim C, Rizzoli SO, Betz WJ. 2003. Synaptic vesicle pools at the frog neuromuscular junction. Neuron 39: 529-541.

Rizzoli SO, Betz WJ. 2005. Synaptic vesicle pools. Nat Rev Neurosci 6: 57-69.

Rosenmund C, Stevens CF. 1996. Definition of the readily releasable pool of vesicles at hippocampal synapses. Neuron 16: 1197-1207.

Rosenmund C, Clements JD, Westbrook GL. 1993. Nonuniform probability of glutamate release at a hippocampal synapse. Science 262: 754-757.

Ruiz R, Cano R, Casanas JJ, Gaffield MA, Betz WJ, Tabares L. 2011. Active zones and the readily releasable pool of synaptic vesicles at the neuromuscular junction of the mouse. J Neurosci 31: 2000-2008.

Ryan TA, Ziv NE, Smith SJ. 1996. Potentiation of evoked vesicle turnover at individually resolved synaptic boutons. Neuron 17: 125-134.

Sakaba T, Neher E. 2001a. Calmodulin mediates rapid recruitment of fast-releasing synaptic vesicles at a calyxtype synapse. Neuron 32: 1119-1131.

Sakaba T, Neher E. 2001b. Quantitative relationship between transmitter release and calcium current at the calyx of held synapse. J Neurosci 21: 462-476.

Sara Y, Virmani T, Deak F, Liu X, Kavalali ET. 2005. An isolated pool of vesicles recycles at rest and drives spontaneous neurotransmission. Neuron 45: 563-573.

Sara Y, Bal M, Adachi M, Monteggia LM, Kavalali ET. 2011. Use-dependent AMPA receptor block reveals segregation of spontaneous and evoked glutamatergic neurotransmission. J Neurosci 31: 5378-5382.

Saviane C, Silver RA. 2006. Fast vesicle reloading and a large pool sustain high bandwidth transmission at a central synapse. Nature 439: 983-987.

Schikorski T, Stevens CF. 1997. Quantitative ultrastructural analysis of hippocampal excitatory synapses. J Neurosci 17: 5858-5867.

Schikorski T, Stevens CF. 2001. Morphological correlates of functionality defined synaptic vesicle populations. $\mathrm{Na}$ ture Neurosci 4: 391-395.

Schneggenburger R, Sakaba T, Neher E. 2002. Vesicle pools and short-term synaptic depression: Lessons from a large synapse. Trends Neurosci 25: 206-212.
Shin OH, Lu J, Rhee JS, Tomchick DR, Pang ZP, Wojcik SM, Camacho-Perez M, Brose N, Machius M, Rizo J, et al. 2010. Munc13 $\mathrm{C}_{2} \mathrm{~B}$ domain is an activity-dependent $\mathrm{Ca}^{2+}$ regulator of synaptic exocytosis. Nat Struct Mol Biol 17: 280-288.

Shtrahman M, Yeung C, Nauen DW, Bi GQ, Wu XL. 2005. Probing vesicle dynamics in single hippocampal synapses. Biophys J 89: 3615-3627.

Sjostrand FS. 1953. The ultrastructure of the inner segments of the retinal rods of the guinea pig eye as revealed by electron microscopy. J Cell Physiol 42: 45-70.

Smith C, Moser T, Xu T, Neher E. 1998. Cytosolic $\mathrm{Ca}^{2+}$ acts by two separate pathways to modulate the supply of release-competent vesicles in chromaffin cells. Neuron 20: $1243-1253$.

Staras K, Branco T, Burden JJ, Pozo K, Darcy K, Marra V, Ratnayaka A, Goda Y. 2010. A vesicle superpool spans multiple presynaptic terminals in hippocampal neurons. Neuron 66: 37-44.

Stevens CF, Sullivan JM. 1998. Regulation of the readily releasable vesicle pool by protein kinase C. Neuron 21 : 885-893.

Stevens CF, Wang Y. 1994. Changes in reliability of synaptic function as a mechanism for plasticity. Nature 371: 704-707.

Stevens CF, Wang Y. 1995. Facilitation and depression at single central synapses. Neuron 14: 795-802.

Stevens CF, Wesseling JF. 1998. Activity-dependent modulation of the rate at which synaptic vesicles become available to undergo exocytosis. Neuron 21: 415-424.

Stevens CF, Wesseling JF. 1999a. Augmentation is a potentiation of the exocytotic process. Neuron 22: 139-146.

Stevens CF, Wesseling JF. 1999b. Identification of a novel process limiting the rate of synaptic vesicle cycling at hippocampal synapses. Neuron 24: 1017-1028.

Stevens CF, Williams JH. 2000. "Kiss and run" exocytosis at hippocampal synapses. Proc Natl Acad Sci 97: 1282812833.

Stevens CF, Williams JH. 2007. Discharge of the readily releasable pool with action potentials at hippocampal synapses. J Neurophysiol 98: 3221-3229.

Südhof TC. 2000. The synaptic vesicle cycle revisited. Neuron 28: $317-320$.

Südhof TC. 2004. The synaptic vesicle cycle. Annu Rev Neurosci 27: 509-547.

* Südhof TC. 2012. Calcium control of neurotransmitter release. Cold Spring Harb Perspect Biol 4: a011353.

* Südhof TC, Rizo J. 2011. Synaptic vesicle exocytosis. Cold Spring Harb Perspect Biol 3: a005637.

Takamori S, Holt M, Stenius K, Lemke EA, Gronborg M, Riedel D, Urlaub H, Schenck S, Brugger B, Ringler P, et al. 2006. Molecular anatomy of a trafficking organelle. Cell 127: $831-846$.

Thiagarajan TC, Lindskog M, Tsien RW. 2005. Adaptation to synaptic inactivity in hippocampal neurons. Neuron 47 : $725-737$.

Tsodyks MV, Markram H. 1997. The neural code between neocortical pyramidal neurons depends on neurotransmitter release probability. Proc Natl Acad Sci 94: 719723. 
A.A. Alabi and R.W. Tsien

Tsuriel S, Fisher A, Wittenmayer N, Dresbach T, Garner CC Ziv NE. 2009. Exchange and redistribution dynamics of the cytoskeleton of the active zone molecule bassoon. $J$ Neurosci 29: 351-358.

von Gersdorff H, Matthews G. 1997. Depletion and replenishment of vesicle pools at a ribbon-type synaptic terminal. J Neurosci 17: 1919-1927.

von Gersdorff H, Vardi E, Matthews G, Sterling P. 1996. Evidence that vesicles on the synaptic ribbon of retinal bipolar neurons can be rapidly released. Neuron 16: $1221-1227$.

Waites CL, Garner CC. 2011. Presynaptic function in health and disease. Trends Neurosci 34: 326-337.

Wang LY, Kaczmarek LK. 1998. High-frequency firing helps replenish the readily releasable pool of synaptic vesicles. Nature 394: 384-388.

Waters J, Smith SJ. 2000. Phorbol esters potentiate evoked and spontaneous release by different presynaptic mechanisms. J Neurosci 20: 7863-7870.

Waters J, Smith SJ. 2002. Vesicle pool partitioning influences presynaptic diversity and weighting in rat hippocampal synapses. J Physiol 541: 811-823.

Welzel O, Henkel AW, Stroebel AM, Jung J, Tischbirek CH, Ebert K, Kornhuber J, Rizzoli SO, Groemer TW. 2011. Systematic heterogeneity of fractional vesicle pool sizes and release rates of hippocampal synapses. Biophys J 100: 593-601.

Wesseling JF, Lo DC. 2002. Limit on the role of activity in controlling the release-ready supply of synaptic vesicles. J Neurosci 22: 9708-9720.
Westphal V, Rizzoli SO, Lauterbach MA, Kamin D, Jahn R, Hell SW. 2008. Video-rate far-field optical nanoscopy dissects synaptic vesicle movement. Science 320: 246-249.

Wilhelm BG, Groemer TW, Rizzoli SO. 2010. The same synaptic vesicles drive active and spontaneous release. Nat Neurosci 13: 1454-1456.

Willig KI, Rizzoli SO, Westphal V, Jahn R, Hell SW. 2006. STED microscopy reveals that synaptotagmin remains clustered after synaptic vesicle exocytosis. Nature 440: 935-939.

Wu LG, Borst JG. 1999. The reduced release probability of releasable vesicles during recovery from short-term synaptic depression. Neuron 23: 821-832.

Wu LG, Saggau P. 1997. Presynaptic inhibition of elicited neurotransmitter release. Trends Neurosci 20: 204-212.

Wyatt RM, Balice-Gordon RJ. 2008. Heterogeneity in synaptic vesicle release at neuromuscular synapses of mice expressing synaptopHluorin. J Neurosci 28: 325-335.

$\mathrm{Xu}$ J, Wu LG. 2005. The decrease in the presynaptic calcium current is a major cause of short-term depression at a calyx-type synapse. Neuron 46: 633-645.

Zenisek D. 2008. Vesicle association and exocytosis at ribbon and extraribbon sites in retinal bipolar cell presynaptic terminals. Proc Natl Acad Sci 105: 4922-4927.

Zhang Q, Cao YQ, Tsien RW. 2007. Quantum dots provide an optical signal specific to full collapse fusion of synaptic vesicles. Proc Natl Acad Sci 104: 17843-17848.

Zucker RS, Regehr WG. 2002. Short-term synaptic plasticity. Annu Rev Physiol 64: 355-405. 


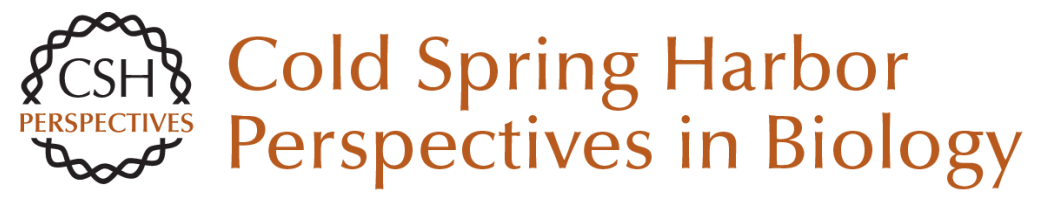

\section{Synaptic Vesicle Pools and Dynamics}

AbdulRasheed A. Alabi and Richard W. Tsien

Cold Spring Harb Perspect Biol 2012; doi: 10.1101/cshperspect.a013680 originally published online June 27, 2012

\section{Subject Collection The Synapse}

Studying Signal Transduction in Single Dendritic Spines Ryohei Yasuda

Synaptic Vesicle Pools and Dynamics AbdulRasheed A. Alabi and Richard W. Tsien

Synapses and Memory Storage Mark Mayford, Steven A. Siegelbaum and Eric $R$. Kandel

Synapses and Alzheimer's Disease Morgan Sheng, Bernardo L. Sabatini and Thomas C. Südhof

\section{Synaptic Cell Adhesion}

Markus Missler, Thomas C. Südhof and Thomas Biederer

Synaptic Dysfunction in Neurodevelopmental Disorders Associated with Autism and Intellectual Disabilities

Huda Y. Zoghbi and Mark F. Bear

The Postsynaptic Organization of Synapses Morgan Sheng and Eunjoon Kim

Presynaptic LTP and LTD of Excitatory and Inhibitory Synapses

Pablo E. Castillo
Synaptic Vesicle Endocytosis

Yasunori Saheki and Pietro De Camilli

Short-Term Presynaptic Plasticity Wade G. Regehr

NMDA Receptor-Dependent Long-Term

Potentiation and Long-Term Depression

(LTP/LTD) Christian Lüscher and Robert C. Malenka

Ultrastructure of Synapses in the Mammalian

Brain Kristen M. Harris and Richard J. Weinberg

Calcium Signaling in Dendritic Spines Michael J. Higley and Bernardo L. Sabatini

Synaptic Neurotransmitter-Gated Receptors Trevor G. Smart and Pierre Paoletti

Synaptic Vesicle Exocytosis

Thomas C. Südhof and Josep Rizo

Vesicular and Plasma Membrane Transporters for Neurotransmitters

Randy D. Blakely and Robert H. Edwards

For additional articles in this collection, see http://cshperspectives.cshlp.org/cgi/collection/

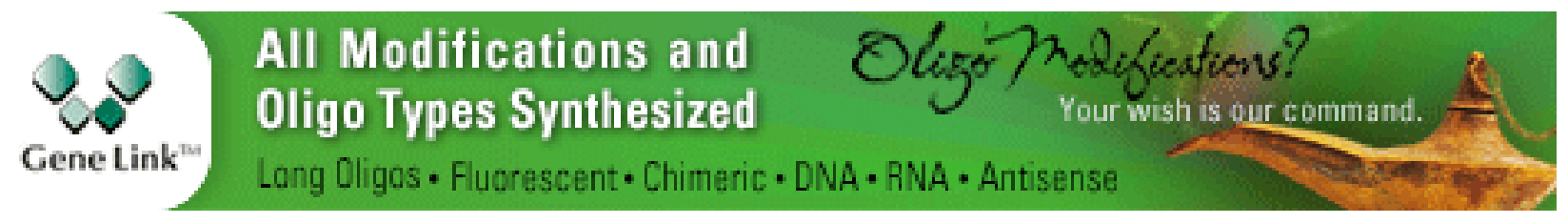

